\title{
Gene expression profiling of progenitor cells isolated from rat rotator cuff musculotendinous junction
}

\author{
Mandeep S. Virk" ${ }^{*}$, Wei Luo ${ }^{2}$, Katie J. Sikes ${ }^{3}$, Jun Li ${ }^{2}$ Anna Plaas² and Brian J. Cole ${ }^{4}$
}

\begin{abstract}
Background: Rotator cuff tendon tears are typically degenerative and usually affect the region of tendon insertion on bone. The remnant torn tendon is degenerative and may not be an ideal source for progenitor cells for cellbased therapies. Therefore, the aim of this study was to determine if musculotendinous junction (MTJ), which is adjacent to tendon would be a viable alternate source of progenitor stem cells. We also sought to study the gene expression profile MTJ progenitors and compare it with progenitors isolated from RC tendon, RC muscle and other existing tissue sources (bone marrow, adipose tissue, and Achilles tendon).

Methods: Rotator cuff tendon (RCT), muscle (RCM), and RCMTJ as well as Achilles tendon (AT) tissues were harvested from healthy male Lewis rats and progenitor cultures were established from these tissues and also from bone marrow and adipose tissue. Quantitative RT-PCR was performed on RNA extracts from intact tissues and progenitor cells using a custom array for the mesenchymal stem cell (MSC) differentiation marker genes. The gene expression profile of MSC differentiation markers within four tissues types, six progenitor cells, and between tissue and their corresponding progenitors were compared.
\end{abstract}

Results: Progenitors cells can be isolated from rat rotator cuff musculotendinous tissue and their pattern of MSC gene expression was similar to the rotator cuff tendon progenitors for majority of the genes tested. However, there were significant differences between the MSC gene expression patterns of RCMTJ and RCM progenitors. Furthermore, there were differences in gene expression between the RCMTJ tissue and its progenitor cells with respect to MSC differentiation markers. The gene expression pattern of RCMTJ tissue was similar to RCM tissue with respect to markers of chondrogenesis, myogenesis, tenogenesis, and MSC specific markers.

Conclusion: We demonstrate that the musculotendinous junction contains distinct set of progenitor cells and their MSC gene expression pattern is similar to rotator cuff tendon progenitors. RCMTJ progenitors will be an attractive option for cell-based regenerative treatment of chronic rotator cuff tears.

Keywords: Progenitor cell, Rotator cuff musculotendinous junction, Bone marrow cells, Rotator cuff tendon, Rotator cuff muscle, MSC gene expression profile

\footnotetext{
* Correspondence: drmandeepvirk@gmail.com

1Department of Orthopaedic Surgery, Division of Shoulder \& Elbow, New

York University Langone Orthopedic Hospital, 301 East 17th street, New York

10003, NY, USA

Full list of author information is available at the end of the article
}

\section{BMC}

c) The Author(s). 2020 Open Access This article is licensed under a Creative Commons Attribution 4.0 International License, which permits use, sharing, adaptation, distribution and reproduction in any medium or format, as long as you give appropriate credit to the original author(s) and the source, provide a link to the Creative Commons licence, and indicate if changes were made. The images or other third party material in this article are included in the article's Creative Commons licence, unless indicated otherwise in a credit line to the material. If material is not included in the article's Creative Commons licence and your intended use is not permitted by statutory regulation or exceeds the permitted use, you will need to obtain permission directly from the copyright holder. To view a copy of this licence, visit http://creativecommons.org/licenses/by/4.0/ The Creative Commons Public Domain Dedication waiver (http://creativecommons.org/publicdomain/zero/1.0/) applies to the data made available in this article, unless otherwise stated in a credit line to the data. 


\section{Background}

Rotator cuff ( $\mathrm{RC})$ tears are one of the most common causes of chronic shoulder pain, with approximately 250, 000 rotator cuff repairs performed in the United States annually [21]. While significant progress has been made in mechanical fixation of rotator cuff tears, failed rotator cuff repairs continue to be a challenge, especially with large tears [16]. Failed repairs of large and massive RC tears result in persistent shoulder pain and loss of shoulder function and eventually lead to shoulder arthritis and poor functional use of the arm [34, 39].

There is continued interest in biologic therapies to improve tendon to bone healing in rotator cuff repairs [2, 6, 29, 31]. The cell-based therapy using progenitor cells is a promising strategy for regeneration and healing of the tendon tissues $[1,6,10,11,19,23$, 24, 26-28, 30, 36, 37]. However, the ideal progenitor cell type, or the critical growth factor involved in tendon-bone repair and ideal scaffold are not known. The tendon-derived progenitor cells (TPCs) have been previously isolated from patellar tendon, and rotator cuff tendon [3, 22, 28, 36, 37]. Rotator cuff tears are commonly degenerative and occur in the region of the tendon insertion. The remnant torn tendon is degenerative and may not be an ideal source for progenitor cells for cell-based therapies. Consequently, rotator cuff tendon is less attractive as a source of tendon progenitor cells for cell-based treatment of chronic rotator cuff tears. However, the adjacent musculotendinous junction is relatively preserved in chronic $\mathrm{RC}$ tendon tears and may be a viable alternate source of progenitor cells. The rotator cuff musculotendinous junction (RCMTJ) is an anatomic transition zone between a muscle and tendon and is a more vascularized region, which is less prone to wear and tear compared to tendon insertion in degenerative rotator cuff tears [13]. If we can isolate tendon progenitors from MTJ, it will be a viable option for harvesting tendon progenitors for cell-based therapies in patients with chronic rotator cuff tears.

In this study, we want to determine if there is a progenitor cell population in RCMTJ and also establish their gene expression profile for mesenchymal stem cell (MSC) differentiation markers. Our hypothesis is that progenitors cells do exist in rotator cuff musculotendinous junction and they are distinct population of cells different from the rotator cuff muscle tissue. Therefore, the purpose of this study was three folds; a) to isolate and characterize the progenitor cells from the rat RCMTJ b) to establish gene expression profile for MSC differentiation markers for native RMTJ tissue and compare it to the RCMTJ progenitors, and other tissues including rotator cuff tendon (RCT), rotator cuff muscle (RCM) and Achilles tendon (AT) and c) to compare the gene expression profiles of progenitor cells derived from RCMTJ, RCM, RCT and other tissues (bone marrow, adipose and Achilles tendon derived progenitor cells).

\section{Methods}

This is a controlled laboratory study, which was performed using rat rotator cuff, Achilles tendon, bone marrow, and adipose tissue. All experiments were performed in triplicate.

\section{Rationale for experiments}

Our first aim was to assess the feasibility of isolating progenitor cells from the rotator cuff musculotendinous junction tissue. Towards this we harvested tissue from the rat RCMTJ and isolated cells from the MTJ tissue. We used the basic property of plastic adherence of progenitor cells to selectively identify and expand the MTJ derived progenitor cell population and subsequently studied their morphology and MSC gene expression pattern.

Our second aim was to compare the MSC gene expression of native tissues (rotator cuff muscle, rotator cuff tendon and rotator cuff musculotendinous junction and Achilles tendon) with the progenitors derived from each corresponding tissue. Towards this, we compared the MSC gene expression profiles of intact tissue RNA extracts with the corresponding progenitors to characterize the differentiated tissue-specific cell population, that exist together with specific progenitors in each individual tissue. We also compared the gene expression of tissue extracts from the rotator cuff muscle, tendon and musculotendinous junction. Our hypothesis for this part of the experiment was that tissues in three locations (rotator cuff muscle, tendon, and musculotendinous junction) should have different MSC gene expression profiles if they are anatomically or functionally distinct zones.

Our third aim was to compare the MSC gene expression profiles of MTJ derived progenitors with the progenitors derived from the $\mathrm{RC}$ muscle and $\mathrm{RC}$ tendon to determine if there is a difference in gene expression at three different locations within the same tissue (rotator cuff). Additionally, we also compared the MSC gene expression pattern of RC-MTJ derived progenitors with progenitors derived from other tendon (Achilles tendon) and non-tendon sources (bone marrow and adipose tissue), which served as controls for these experiments.

\section{Ethics statement and animal euthanasia}

We obtained ethical approval from the Institutional Animal Care and Use Committee of Rush University Medical Center. 


\section{Tissue harvest}

A total of 9 male Lewis rats were used for this experiment (three rats per experiment and total of three experiments). The three experiments were performed on three different days. Tissue collections for RNA purification and cell isolation were performed immediately after sacrifice. The rotator cuff muscle, tendon (close to insertion), and musculotendinous junction tissues as well as the Achilles tendon were harvested from male mature Lewis rats (16-20 weeks old). The rotator cuff tissue was harvested after removing the skin, subcutaneous tissue, and deltoid from both shoulder girdles [8]. The overlying coracoacromial arch was removed to facilitate further exposure of rotator cuff tendons. The musculotendinous junction is a transition zone that contains a mix of muscle and tendon and spreads/extends over a broader area and not a single demarcation line. Notably, in the rat, rotator cuff muscle and tendon are sufficiently large to facilitate the macroscopic identification of this region. The RCT, RCM, and RCMTJ were delineated by visual inspection and tissue harvested using a surgical knife blade (Fig. 1). The harvested RCT, RCM, and RCMTJ tissue was immediately transferred to liquid nitrogen.

The Achilles tendon was harvested from both lower extremities as described previously [7]. A midline posterior incision was made on the hind limb of the animal. After subcutaneous dissection, the Achilles tendon was exposed and freed from the plantaris tendon and overlying paratenon. The Achilles tendon was cut from its insertion and harvested with a surgical knife blade avoiding any contamination from the musculotendinous junction. The harvested Achilles tendon tissue was immediately transferred to liquid nitrogen.

\section{Isolation and culture of murine progenitor cells}

A total of 15 Lewis rats were used for this experiment (five rats per experiment and total of three experiments). Progenitor cells were isolated from Achilles tendon, bone marrow, adipose tissue, rotator cuff muscle, tendon, and musculotendinous junction. The adipose tissue (AdT) was harvested from the inguinal fat as described previously [25]. The RCM, RCT, RCMTJ, and AT tissues were harvested as described above. The harvested tissues (RCM, RCT, RCMTJ, AdT, and AT) were handled in a similar fashion for progenitor cell harvest and culture. The harvested tissue was minced and placed into CO2independent medium (Gibco, Gaithersburg, MD) with 3 $\mathrm{mg} / \mathrm{ml}$ collagenase type I (Worthington, Lakewood, NJ) and dispersed under agitation for $2 \mathrm{~h}$ at $37^{\circ} \mathrm{C}$. The digest was then centrifuged at $300 \mathrm{~g}$ for $10 \mathrm{~min}$. The supernatant lipid-rich layer was discarded, and the pellet treated with $1.5 \mathrm{~mL}$ RBC lysis buffer (eBioscience, Waltham, MA). The pellet was then washed three times in PBS, before suspension in $60 \mathrm{~mL}$ of DMEM $/ 5 \mathrm{mM}$ glucose $/ 10 \%$ FBS (Atlanta Biologics) containing $2 \mathrm{ng} / \mathrm{mL}$ bFGF, (R\&D) and plated into two T75 flasks (Corning). The typical cell yield of the collagenase isolates was approximately $1-2^{\wedge} 6$ cells. However, we observed variable attachment of cells after the $24 \mathrm{~h}$ adherence phase. Thus, based on the density of adherent cells this varied

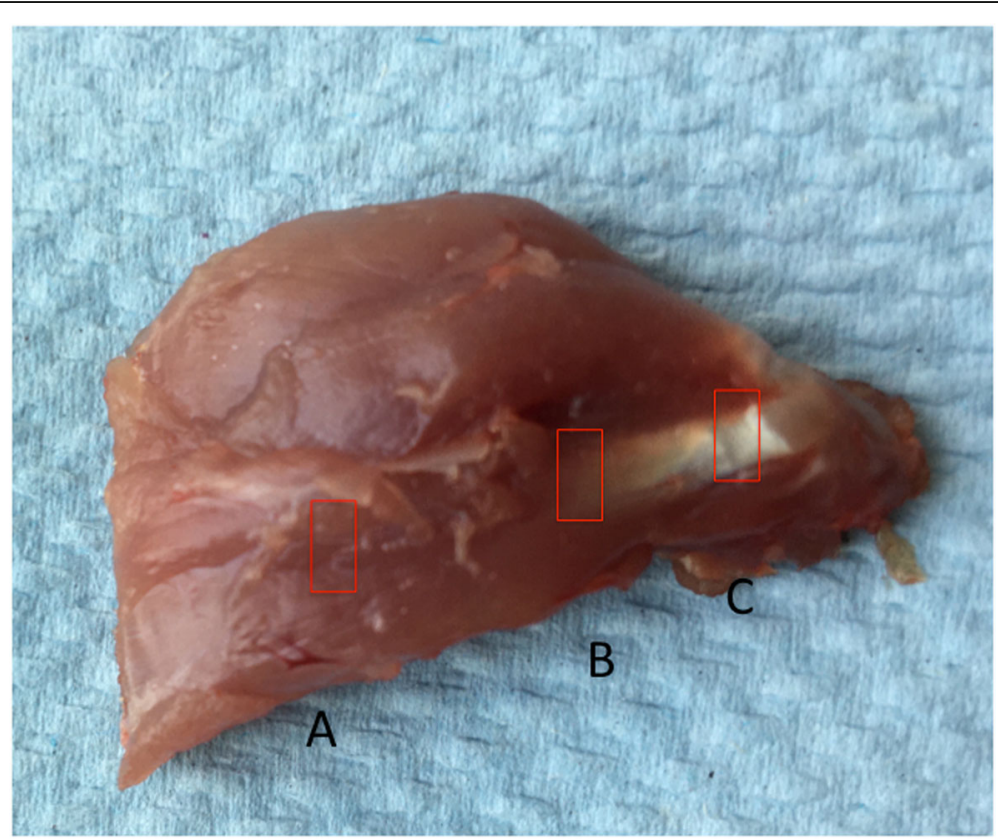

Fig. 1 Rat rotator cuff tissue showing three different sites of tissue harvest for progenitor cell isolation [rotator cuff muscle (a), musculotendinous junction (b) and tendon insertion (c)] 
between $0.5-1 \times 10^{\wedge} 6$ cells per T75 flask. Nonadherent cells were removed after $24 \mathrm{~h}$ and fresh medium was added. Medium changes were performed every $48-72 \mathrm{~h}$ until cells reach confluency of $\sim 90 \%$ between days $8-10$ post plating. The cell yield after trypsinization of each T75 flask was approximately $6-6.5 \times 10^{\wedge} 6$ cells. These cell suspensions were equally divided between three T25 flasks (Corning) and plated at the density of approximately $2-2.5^{\wedge} 6$ cells, which resulted in $\sim 90 \%$ confluency immediately after cells adhered, thus minimizing additional proliferation of the passaged cells prior to RNA extractions.

Bone marrow was harvested from the femurs and tibias under sterile conditions according to a previously published protocol [38]. Briefly, the whole bone marrow was obtained under sterile conditions by flushing the marrow cavity with Iscove's modified Dulbecco's medium (Irvine Scientific, Santana, CA) in a $30 \mathrm{cc}$ syringe and 18-gauge needle. The resulting cell suspension was centrifuged at $300 \mathrm{~g}$ for $10 \mathrm{~min}$. The pellet was then suspended in $30 \mathrm{~mL}$ of medium (DMEM/5 mM glucose/
$10 \%$ FBS containing $2 \mathrm{ng} / \mathrm{mL}$ bFGF) and plated in T75 flasks and treated further like rotator and Achilles tendon cells.

General morphological characteristics during the primary culture and the subsequent passage were evaluated under light microscope. Specifically, elongated cell shapes, multiple plasma membrane extension, absence of apoptotic nuclear changes, intercellular spaces, and absence of dense packing and fibroblastic alignments were similar for both, primary and first passage cells.

\section{Quantitative real time PCR}

RNA was isolated from the intact tissue (following fragmentation in a Bessman tissue pulverizer at $-196^{\circ} \mathrm{C}$ ) and from MSCs [passage 2 (P2)] via TRIzol $^{\circ}$ extraction (Invitrogen, Grand Island, NY) as previously described [4, 20, 33]. Briefly, RNA was purified with an RNeasy MiniKit (Qiagen, Valencia, CA) with RNA concentration and purity (A260/280 > 1.9) analyzed using a Nanodrop (ND-1000, Thermoscientific Waltham, MA). cDNA was synthesized using Qiagen RT2 First Strand kit.

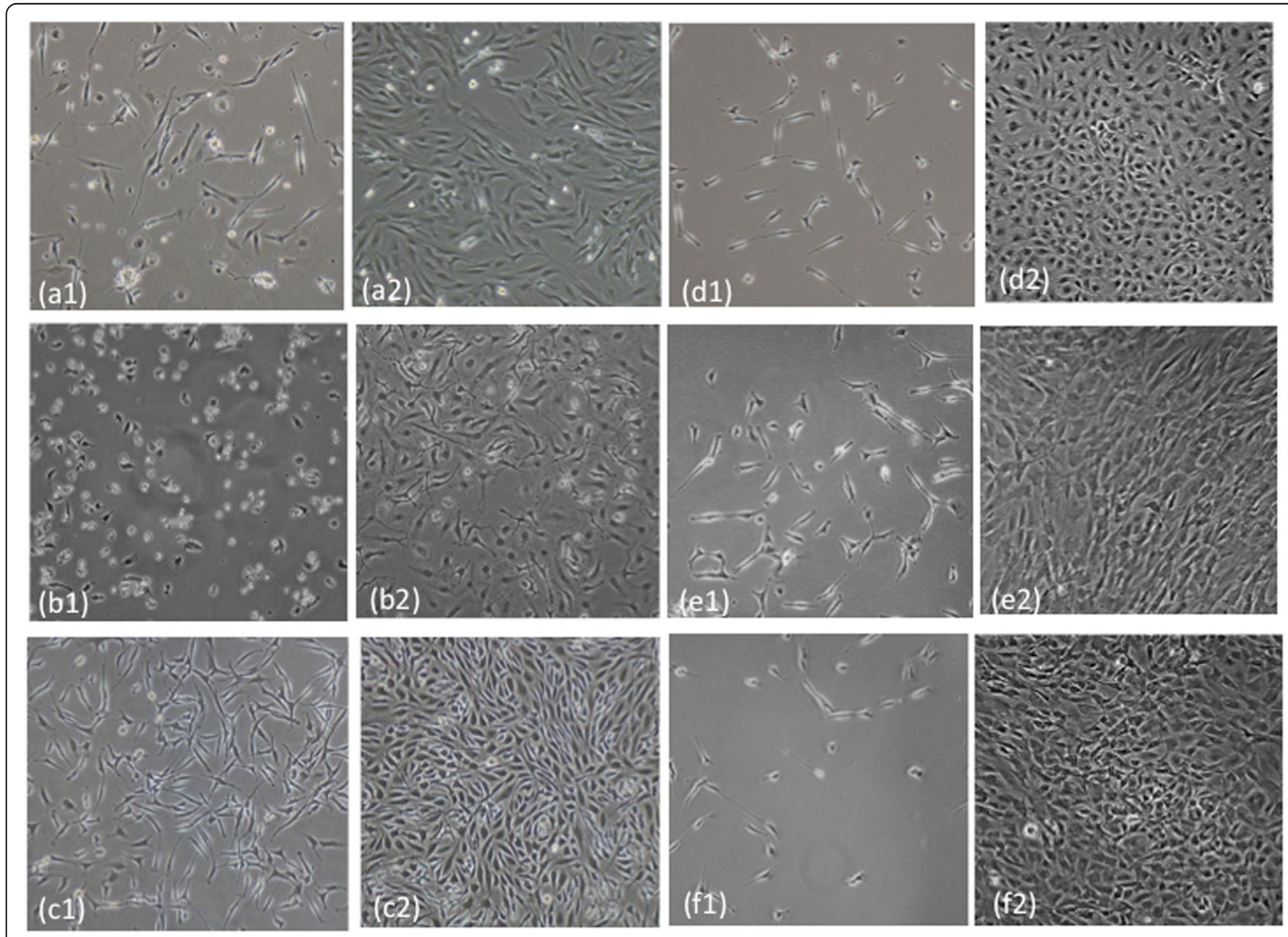

Fig. 2 Phase contrast images of cultured stromal fibroblasts at $24 \mathrm{~h}$ post plating (a1-f1) and at confluency (a2-f2). Gene expression analyses were performed on confluent cells only. (a-ADSC; b-BMSC; c-AT; d-RCT; e-RCM; f-RCMTJ) 
(A) Stemness Markers

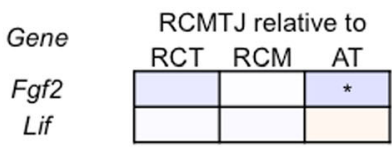

(B) MSC Specific Markers

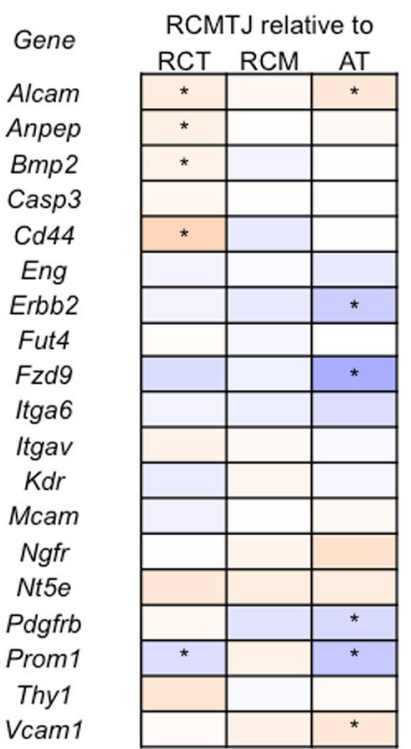

(C) Other MSC Markers

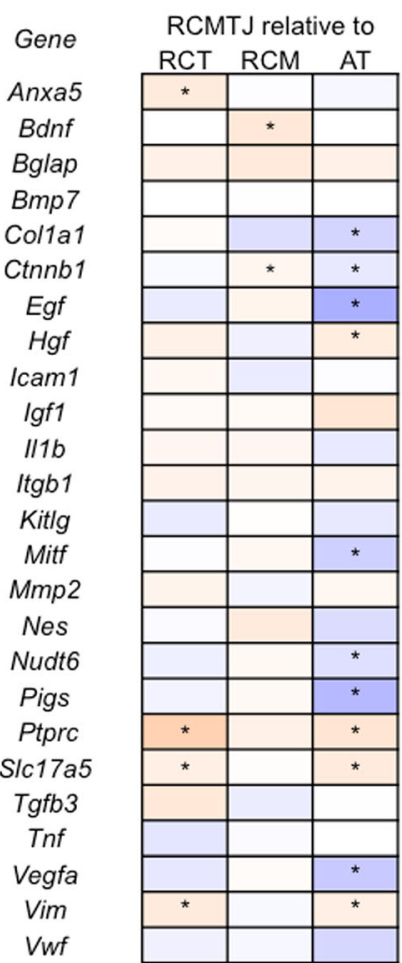

(D) Tenogenesis Markers

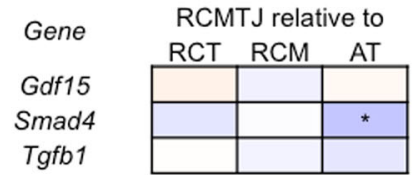

\section{(E) Myogenesis Markers}

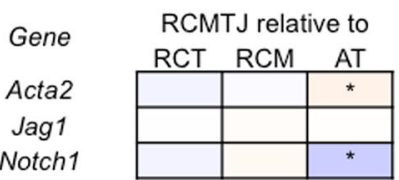

\section{(F) Adipogenesis Markers}

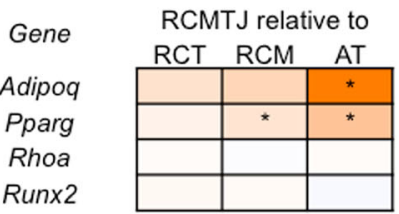

\section{(G) Chondrogenesis Markers}

\begin{tabular}{l|l|l|l|}
\multirow{2}{*}{ Gene } & \multicolumn{3}{c}{ RCMTJ relative to } \\
\cline { 2 - 4 } RCT & RCM & AT \\
\cline { 2 - 4 } Bmp4 & & & \\
\cline { 2 - 4 } Bmp6 & & & \\
\cline { 2 - 4 } Gdf6 & & & \\
\cline { 2 - 4 } Gdf7 & & & \\
\cline { 2 - 4 } Hat1 & & & \\
\cline { 2 - 4 } Itgax & & & \\
\cline { 2 - 4 } Sox9 & $*$ & & \\
\cline { 2 - 4 } Tgfb1 & & & \\
\cline { 2 - 4 } & & & \\
\cline { 2 - 4 } & & &
\end{tabular}

\section{(H) Osteogenesis Markers}

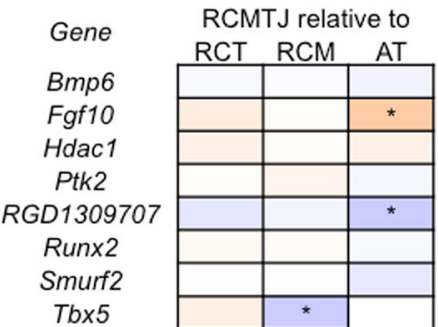

Legend

${ }^{*} p<0.05$ relative to $R C M T J$

Down-regulated 330 -fold

Fig. 3 (See legend on next page.) 
(See figure on previous page.)

Fig. 3 Heat map representation of the fold change in expression of (a) stemness markers, b MSC specific markers, $\mathbf{c}$ other MSC markers, $\mathbf{d}$

tenogenesis markers, e myogenesis markers, $\mathbf{f}$ adipogenesis markers, $\mathbf{g}$ chondrogenesis markers, and (h) osteogenesis markers for the comparison of rotator cuff myotendinous junction (RCMTJ) tissue to rotator cuff tendon (RCT) tissue, rotator cuff muscle (RCM) tissue, and Achilles tendon (AT) tissue. The following genes were not detected: Csf2, Csf3, Fut1, Gnf4, Hnf1a, Ifng, II6, II10, Ins2, Pou5s1, Sox2, and Tert

Quantitative RT-PCR gene expression of rat rotator cuff (RCM, RCT, and RCMTJ) and Achilles tendon (AT) tissue, and their corresponding cultured progenitors cells (RCMC, RCTC, RCMTJC, ATC) and other cultured progenitor cells (BMSC and ADSCs) were profiled using the Rat Mesenchymal Stem Cell $\mathrm{RT}^{2}$ Profiler $^{\mathrm{Tm}}$ PCR Array (PARN-082ZA, Qiagen, Valencia CA). A total of 84 genes were tested and included genes representing markers of stemness, chondrogenesis, tenogenesis, adipogenesis, osteogenesis, and MSC specific and other MSC markers.

\section{Data analysis}

The data was expressed as fold change of mRNA abundance in RCT MTJ tissue and progenitor cells compared to other tissue or progenitor cells, which was calculated as follows. First, the $\Delta \mathrm{Ct}$ relative to the housekeeping gene $\mathrm{B} 2 \mathrm{~m}$ was calculated for each tissue and progenitor cell for each MSC gene. Then, the $\Delta \Delta \mathrm{Ct}$ which $=\Delta \mathrm{Ct}$ RCMTJ $\Delta \mathrm{Ct}$ (reference tissue) and finally the fold change $\left(2^{\wedge}\right.$ $\Delta \Delta \mathrm{Ct}$ ) was calculated. For the tissue to cell comparison, the $\Delta \Delta \mathrm{Ct}$ ends up being $\Delta \mathrm{Ct}$ Cell $-\Delta \mathrm{Ct}$ tissue. All statistical testing was performed on the $\Delta \mathrm{Ct}$ values using Graph Pad Prism 5 (La Jolla, CA), and the fold changes are presented for easier interpretation. A 1-way ANOVA with Tukey's post-hoc tests was utilized over other types of statistical testing as the primary focus for biological relevance 1) differences between different cell and tissue types, and 2) tissue and cell specific comparisons. A $p$ value of $p<0.05$ was considered significant.

\section{Results}

MTJ progenitor cell isolation, and growth and morphology (RCMTJC) in culture conditions

The progenitor cells from the rotator cuff MTJ (RCMTJC) were isolated using standard harvest and culture protocol similar to that used for isolating progenitors from rotator cuff muscle and tendon. We used the basic property of plastic adherence of progenitor cells to selectively identify and expand the MTJ derived progenitor cell population in tissue culture. There were no specific morphological characteristics of progenitors isolated from RCMTJCs and there were no significant differences in morphology and growth characteristics compared to progenitors isolated from RCM or RCT (Fig. 2).

\section{MSC gene expression profile of rotator cuff musculotendinous junction tissue}

MSC gene expression profile of RCMTJ tissue was very similar to that of RCM tissue except for a significant increase in expression of one osteogenesis marker, Tbx5, and a significant decrease in expression of two MSC markers (Ctnnb1 and Bdnf) and one marker of adipogenesis (Pparg; Fig.3). Conversely, significant differences in gene expression of various MSC genes between the RCMTJ and RCT or AT were found (Fig.3). RCMTJ was similar to RCT for MSC differentiation markers for osteogenesis, myogenesis and tenogenesis but there was significant down regulation of MSC specific markers (Alcam, Anpep, CD44, and BMP-2), other MSC markers (Anxa5, Ptprc, Slc17a5, and Vim), and Itgax, a chondrogenesis marker. One of the MSC specific markers, Prom1, was upregulated in RCMTJ compared to RCT.

Compared to AT, the RCMTJ tissue had significant up regulation of number of genes including myogenesis marker, Notch1, tenogenesis marker, Smad4, osteogenesis marker, RGD130970, stemness marker, Fgf2, MSC specific markers, Erbb2, Fzd9, Pdgfrb, and Prom1, and other MSC markers (Col1a1, Ctnnb1, Egf, Pigs, Nudt 6, Mitf, Vwf, and Vegfa). However, AT tissue had significantly higher expression of MSC specific markers, Alcam, Hgf, Vcam1, Hgf, Ptprc, Slc17a5 and Vim, and markers of adipogenesis (Adipoq and Pparg), and osteogenesis (Fgf10). There were no significant differences between the RCMTJ and AT with respect to markers of chondrogenesis.

\section{Differences between progenitor cell and tissue MSC gene expression in rotator cuff musculotendinous junction tissue}

We compared the MSC gene expression profiles of intact tissue RNA extracts with the corresponding progenitors to characterize the differentiated tissue-specific cell population, that exist together with specific progenitors in each individual tissue (Fig. 4) Of the 84 genes tested, significant differences in expression of 45 genes (increased expression in 34 genes and decreased expression in 11 genes) were detected between the RCMTJ and its progenitor cell population (RCMTJC) as shown in Fig. 4. However, these differences between tissue and cells were not specific to RCMTJ and were also seen with other tissues (AT, RCT and RCM) and their corresponding progenitors. 


\section{(A) Stemness Markers}

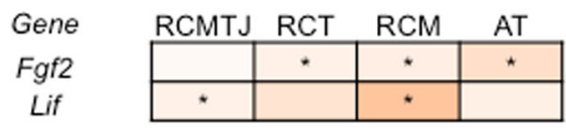

(B) MSC Specific Markers

\begin{tabular}{|c|c|c|c|c|}
\hline Gene & RCMTJ & $\mathrm{RCT}$ & $\mathrm{RCM}$ & AT \\
\hline Alcam & * & * & * & * \\
\hline Anpep & * & $*$ & * & $*$ \\
\hline Bmp2 & * & & * & ** \\
\hline Casp3 & $*$ & $*$ & * & $*$ \\
\hline $\mathrm{Cd} 44$ & * & & * & $*$ \\
\hline Eng & & & & \\
\hline Erbb2 & * & $*$ & * & $*$ \\
\hline Fut4 & & $*$ & * & \\
\hline Itga6 & * & & & \\
\hline Itgav & $*$ & * & * & $*$ \\
\hline$K d r$ & $*$ & $*$ & * & $*$ \\
\hline Mcam & $*$ & * & * & * \\
\hline Ngfr & * & & & \\
\hline$N t 5 e$ & $*$ & $*$ & * & $*$ \\
\hline Pdgfrb & $*$ & & * & $*$ \\
\hline Thy1 & $*$ & $*$ & * & * \\
\hline Vcam1 & $*$ & & * & \\
\hline
\end{tabular}

\section{(C) Other MSC Markers}

Gene Anxa5 Bdnf

Bglap

Col1a1

Ctnnb1

Egf

Hgf

Icam1

Igf1

$\| 1 b$

Itgb1

Kitlg

Mitf

Mmp2

Nes

Nudt6

Pigs

Ptprc

Sic17a5

Tgfb3

Tnf

Vegfa

Vim

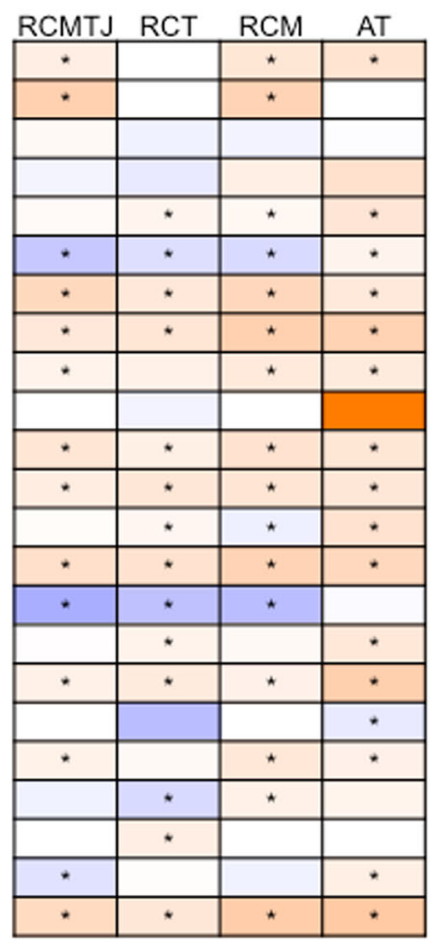

Gene

Gdf15

Smad4

Tgfb1

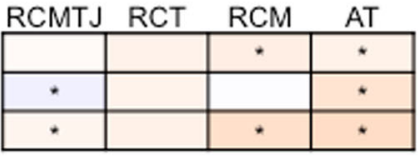

(E) Myogenesis Markers

Gene

Acta2

Jag1

Notch1

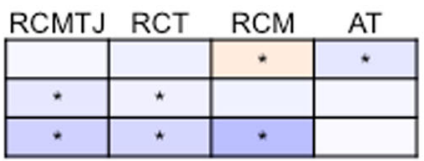

(F) Adipogenesis Markers

Gene

Adipoq

Pparg

Rhoa

Runx2

RCMTJ RCT
\begin{tabular}{|c|c|c|c|}
\hline$*$ & RCM & AT \\
\hline$*$ & & & $*$ \\
\hline & $\star$ & $*$ & $\star$ \\
\hline$*$ & $*$ & $*$ & $\star$ \\
\hline
\end{tabular}

\section{(G) Chondrogenesis Markers}

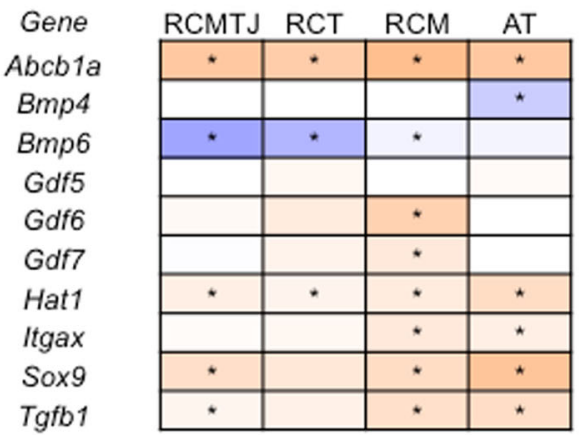

\section{(H) Osteogenesis Markers}

\section{Gene \\ Bmp6 \\ Fgf10 \\ Hdac1 \\ Ptk2 \\ RGD1309707 \\ Runx2 \\ Smurf2}

Tbx5

RCMTJ
\begin{tabular}{|c|c|c|c|}
\hline$\star$ & $*$ & $\star$ & \\
\hline$\star$ & $\star$ & $\star$ & $\star$ \\
\hline$\star$ & $\star$ & $\star$ & $\star$ \\
\hline & & $\star$ & $\star$ \\
\hline & $\star$ & $\star$ & $\star$ \\
\hline$\star$ & $\star$ & $\star$ & $\star$ \\
\hline & & $\star$ & $\star$ \\
\hline$\star$ & & $\star$ & \\
\hline
\end{tabular}

Legend

* $p<0.05$ relative to native tissue

Down-regulated 4973-fold

Fig. 4 (See legend on next page.) 
(See figure on previous page.)

Fig. 4 Heat map representation of the fold change in expression of (a) stemness markers, b MSC specific markers, $\mathbf{c}$ other MSC markers, d

tenogenesis markers, e myogenesis markers, $\mathbf{f}$ adipogenesis markers, $\mathbf{g}$ chondrogenesis markers, and (h) osteogenesis markers for the comparison of progenitor cells relative to correponding tissue for rotator cuff myotendinous junction (RCMTJ), rotator cuff tendon (RCT), rotator cuff muscle (RCM), and Achilles tendon (AT). The following genes were not detected: Bmp7, Csf2, Csf3, Fut1, Fzd9, Hnf1a, Ifng, II10, IL6, Ins2, Prom1, Pou5s1, Sox2, Tert, and Vwf

\section{MSC gene expression profile of MTJ progenitor cells (RCMTJC)}

We compared the MSC gene expression profile in progenitor cells isolated from six sources [rotator cuff muscle (RCMC), tendon (RCTC) and musculotendinous junction (RCMTJC), adipose derived cells (ADSC), bone marrow derived cells (BMSC), and Achilles derived cells (ATSC; Fig. 5)].

The gene expression of RCMTJCs was very similar to that of RCTCs except for the down regulation of 2 genes, GDF 15 (marker of tenogenesis) and Vcam1 (MSC-specific marker). When compared to the MSC gene expression of RCMCs, the RCMTJCs had decreased expression of 26 MSC genes, which included MSC differentiation markers as well as stemness and MSC specific markers. Additionally, one marker of tenogenesis (Tgf-B) and one marker of myogenesis (Acta-2) were down regulated in RCMTJCs but there were no significant differences between the two cell types with respect to other markers of tenogenesis and myogenesis ( $\operatorname{Smad} 4$, Gdf15, Jag1, Notch1). Two markers (osteogenesis marker Fgf10, and MSC specific marker Anpep) were upregulated in RCMTJC compared to RCMC.

There were widespread differences in gene expression (up regulation and down regulation) between the RCMTJC and non-rotator cuff derived progenitor cells (ADSC, BMSC, and ATC) for all gene groups including the MSC differentiation markers and MSC specific and stemness markers, which represents the inherent differences due to different tissue origin of these cells.

\section{Discussion}

The results of this study demonstrate that progenitor cells can be harvested from the rotator cuff musculotendinous junction. The MSC gene expression profile of progenitors isolated from the musculotendinous junction was similar to the rotator cuff tendon progenitors but significantly different compared to rotator cuff muscle progenitors (up regulation of 2 genes and down regulation of 26 genes) and also from the progenitor cells isolated from non-rotator cuff tissue (bone marrow, adipose tissue and Achilles tendon).

Although, progenitor cells have been previously isolated from tendon tissue from different anatomic locations including the rotator cuff, this is the first study to demonstrate their presence in the musculotendinous junction [3, 22, 28, 36, 37]. Furthermore, the MSC gene expression profile of the progenitors isolated from MTJ was strikingly different from the MTJ tissue itself, which confirms that these progenitors are a distinct population in the musculotendinous junction of rotator cuff. Zhang and Wang in an in vitro study demonstrated that progenitors isolated from the tendon exhibit distinct properties compared to tenocytes, including differences in cell marker expression, proliferative and differentiation potential, and cell morphology in culture, which is similar to the results found in this study [41].

It has been postulated that engineered tendon tissue has the potential to recapitulate the structural organization of the rotator cuff enthesis but this regeneration will require concerted interplay of multiple players including progenitor cells, growth factors, mechanical fixation, and vascular supply [30, 35, 40]. Progenitor cells have been isolated from healthy tendon (TPC) but factors regulating extracellular matrix production and its regulation are poorly understood [3, 12, 22, 28, 36, 37]. Therefore, the search for ideal progenitor cell for tendon regeneration continues. In this study, we have shown that progenitor cells are present in the rotator cuff MTJ region and are similar to rotator cuff tendon derived progenitors. These findings have future clinical applications in the field of regenerative medicine. In large, massive rotator cuff tears, there is considerable loss of tendon tissue and the residual tendon tissue is degenerative with presence of fatty infiltration, delamination, and poor tissue quality. The MTJ is relatively preserved in the majority of rotator cuff tears and based on the results of our study has potential to be alternate source of autologous progenitor cells for cell based therapeutic strategies for tendon regeneration. Furthermore, the gene expression of MTJ progenitors being similar to tendon progenitors is likely to provide a similar autocrine and paracrine influences on rotator cuff tendon region. However, this hypothesis will require future testing in vivo using animal models and in clinical studies.

Recently, other investigators have explored the gene expression profile of human rotator cuff tendons $[5,9,17,22,32]$. Chaudhary et al. demonstrated up regulation of extracellular matrix remodeling genes (some matrix metalloproteinases, and metalloproteinase genes, and disintegrin) and down regulation of some interleukins genes (1,8 and 27) in tissue samples from human rotator cuff tendon tears compared to normal controls [5]. Choo et al. demonstrated that there was up regulation of genes associated with fatty atrophy and 


\section{(A) Stemness Markers}

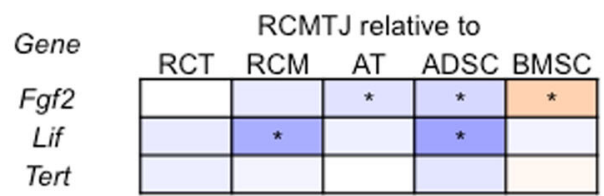

(B) MSC Specific Markers

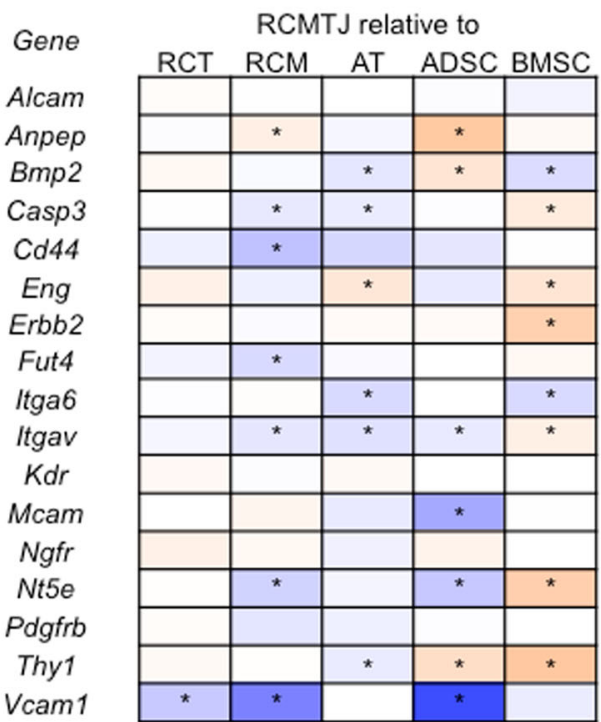

(C) Other MSC Markers

Gene

Anxa5

Bdnf

Bglap

Col1a1

Ctnnb1

Egf

Hgf

Icam1

$\operatorname{lgf1}$

116

Itgb1

Kitlg

Mitf

Mmp2

Nes

Nudt6

Pigs

Sic17a5

Tgfb3

Vegfa

Vim

\section{(D) Tenogenesis Markers}

Gene

Gdf15

Smad4

Tgfb1

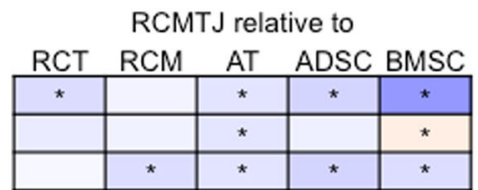

(E) Myogenesis Markers

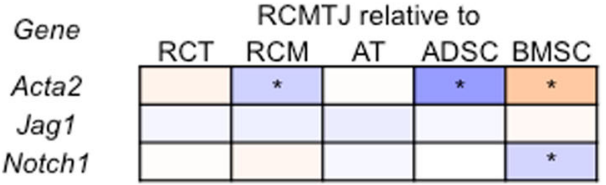

\section{(F) Adipogenesis Markers}

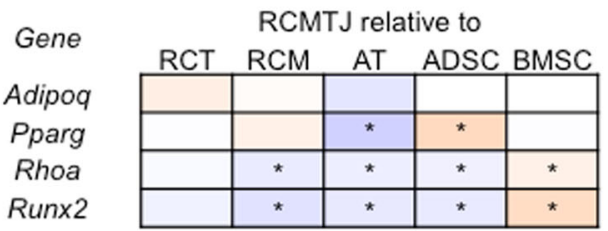

\section{(G) Chondrogenesis Markers}

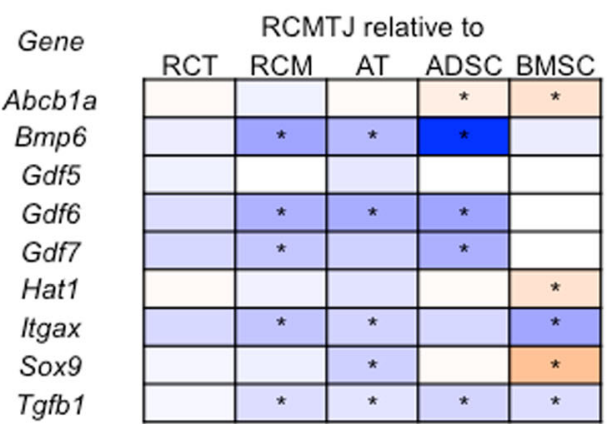

(H) Osteogenesis Markers

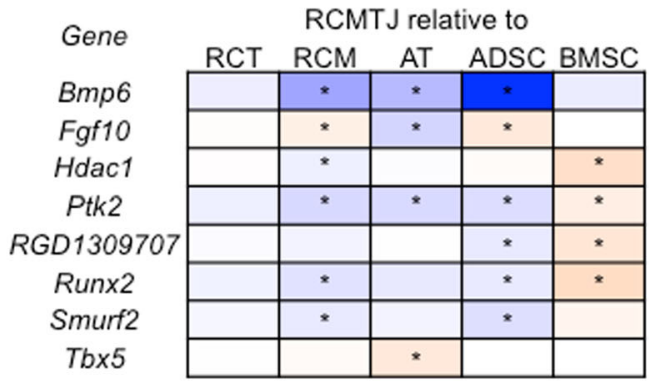

Legend

${ }^{*} p<0.05$ relative to $R C M T J$

Down-regulated 837-fold $\square$ Up-regulated 837-fold 
(See figure on previous page.)

Fig. 5 Heat map representation of the fold change in expression of (a) stemness markers, b MSC specific markers, c other MSC markers, d tenogenesis markers, e myogenesis markers, $\mathbf{f}$ adipogenesis markers, $\mathbf{g}$ chondrogenesis markers, and (h) osteogenesis markers for the comparison of rotator cuff myotendinous junction cells (RCMTJC) to rotator cuff tendon cells (RCTC), rotator cuff muscle cells (RCMC), Achilles tendon cells (ATC), adipose derived stem cells (ADSCs) and bone marrow derived stem cells (BMSCs). The following genes were not detected: Bmp4, Bmp7, Csf2, Csf3, Fut1, Fzd9, Hnf1a, Ifng, Il10, IL1b, Ins2, Prom1, Ptprc, Pou5s1, Sox2, Tnf and Vwf

fibrosis in full thickness rotator cuff tears compared to massive rotator cuff tears, which demonstrated down regulation of all gene programs except inhibition of myogenesis [9]. In contrast to aforementioned studies, we have characterized the MSC gene expression profile in progenitors isolated from normal rotator cuff musculotendinous junction without the presence of rotator cuff tear. We found that the gene expression for MSC markers of tenogenesis and myogenesis was preserved among the three cell types isolated from rotator cuff tissue and may reflect the functional similarity between these three cell types (musculoskeletal origin). Interestingly, the expression of adipogenesis markers was significantly down regulated in the RCMTJ progenitors compared to RCM progenitors, ADSCs and BMSCs. The differential in lineage specific gene expressions may simply be a result of the basal level of 'growth' factors/cytokines provided by the FBS preparation used, as well as autocrine production of such differentiation factors. Thus, further experimentation in needed to define the similarity/differences in the multipotency as well as the differentiation capabilities of the cells.

The progenitor cells from bone marrow had higher expression of stemness markers and MSC markers compared to MTJ cells. At this stage we have no experimentbased explanation for the differences. However, we hypothesize that each progenitor cell population consists of multiple types, either in terms of lineage or differentiation stage that would include the tissue per se as well as 'auxillary' tissue structures such as the peritenon, endomysium, blood vessels etc. A quantitative cell sorting approach followed by gene expression analyses of subpopulations would be needed test this possibility [18].

\section{Limitations}

This study has potential limitations, which should be taken into consideration when interpreting the results. First, the RT-PCR array technology generates vast volumes of data and data interpretation can be subject to interpretive bias depending on the genes tested. However, we have reported our results on all the 84 genes tested to minimize this bias. Secondly, genes can be subjected to post-translational modifications at multiple levels and the up regulation in gene expression may not result in protein translation. Third, the rotator cuff tissue evaluated in this study was from healthy rats without any obvious signs of rotator cuff disease. Therefore, it is possible that gene expression profiles in diseased conditions may be different compared to healthy rotator cuff tissue. Fourth, while the expression profile for stemness and differentiation markers were performed, the differentiation assays to determine how the cells differentiate under certain conditions were not performed. We used the term progenitors for the cultured cells, but they are more of a heterogeneous population of cells. To establish the 'progenitor cell nature' of the cultures, they were established following methodologies previously described for progenitor cell culture and expansion from equine, bovine and mouse tissue sources [14, 15]. Finally, the cell populations in rat rotator cuff can be different from human rotator cuff especially given the fact that humans don't use the upper extremity for ambulatory weight bearing in addition to the inherent biological differences. Furthermore, it is important to note that the MSC markers in rats differ compared to humans.

\section{Conclusion}

This study demonstrates that progenitor cells can be harvested from the musculotendinous junction of a rat rotator cuff. The gene expression of MTJ progenitors is similar to tendon progenitors but considerably different from muscle derived progenitors or other non rotator cuff derived progenitors (adipose, bone marrow and Achilles tendon). However, further detailed experimentation, including cell sorting approaches with stemness markers to obtain populations with differentiation potentials for expression of muscle and tendon specific characteristic is required to further establish clinically relevant use of such cells in the treatment of tendon disorders.

\footnotetext{
Abbreviations

MSCs: Mesenchymal Stromal Progenitor Cells; RC: Rotator cuff; RCT: Rotator cuff tendon; RCM: Rotator cuff muscle; RCMTJ: Rotator cuff

musculotendinous junction; AT: Achilles tendon; RT-PCR: Reverse transcriptase-polymerase chain reaction; TPCs: Tendon-derived progenitor cells; DMEM: Dulbecco's modified eagle medium; FBS: Fetal bovine serum; bFGF: beta fibroblast growth factor; mRNA: Messenger ribonucleic acid; DNA: Deoxyribonucleic acid; Ct: Cycle threshold; ANOVA: Analysis of Variance; ADSC: Adipose derived cells; BMSC: Bone marrow derived cells; ATSC: Achilles tendon derived cells
}

\section{Acknowledgements}

None.

Authors' contributions

All authors have read and approved the manuscript. Substantial contributions to research design (MSV,AP,BJC, LW), or the acquisition, analysis or interpretation of data (MSV, AP, BJC, LW, KJS, JL). Drafting the paper or 
revising it critically; MSV, LW, KJS,JL, AP, BJC. Approval of the submitted and final versions: MSV, LW, KJS,JL, AP, BJC.

\section{Funding}

None.

\section{Availability of data and materials}

The datasets used and/or analyzed during the current study are available from the corresponding author on reasonable request.

\section{Ethics approval and consent to participate}

We obtained ethical approval from the Institutional Animal Care and Use Committee of Rush University Medical Center.

\section{Consent for publication}

Not applicable.

\section{Competing interests}

The authors declare that they have no competing interests.

\section{Author details}

${ }^{1}$ Department of Orthopaedic Surgery, Division of Shoulder \& Elbow, New York University Langone Orthopedic Hospital, 301 East 17th street, New York 10003, NY, USA. ²Dept of Internal Medicine, Rush University Medical Center, 1735 W Harrison St Jelke 1302, Chicago 60612, IL, USA. ${ }^{3}$ Department of Clinical Sciences, Colorado State University, Translational Medicine Institute, Fort Collins 80523, CO, USA. ${ }^{4}$ Department of Orthopaedic Surgery, Sports and Shoulder and Elbow Division, Midwest Orthopaedics at Rush University, 1611 West Harrison Suite 300, Chicago, IL, USA.

Received: 18 August 2019 Accepted: 5 March 2020

Published online: 28 March 2020

\section{References}

1. Ahmad Z, Wardale J, Brooks R, Henson F, Noorani A, Rushton N. Exploring the application of stem cells in tendon repair and regeneration. Arthroscopy. 2012;28:1018-29. https://doi.org/10.1016/j.arthro.2011.12.009.

2. Bedi A, Maak T, Walsh C, Rodeo SA, Grande D, Dines DM, et al. Cytokines in rotator cuff degeneration and repair. J Shoulder Elb Surg. 2012;21:218-27. https://doi.org/10.1016/j.jse.2011.09.020.

3. Bi Y, Ehirchiou D, Kilts TM, Inkson CA, Embree MC, Sonoyama W, et al. Identification of tendon stem/progenitor cells and the role of the extracellular matrix in their niche. Nat Med. 2007;13:1219-27. https://doi.org/ 10.1038/nm1630.

4. Bittermann A, Gao S, Rezvani S, Li J, Sikes KJ, Sandy J, et al. Oral Ibuprofen interferes with cellular healing responses in a murine model of Achilles tendinopathy. J Musculoskelet Disord Treat. 2018;4. https://doi.org/10.23937/ 2572-3243.1510049.

5. Chaudhury S, Xia Z, Thakkar D, Hakimi O, Carr AJ. Gene expression profiles of changes underlying different-sized human rotator cuff tendon tears. J Shoulder Elb Surg. 2016;25:1561-70. https://doi.org/10.1016/j.jse.2016.02.037.

6. Chen $\mathrm{CH}$, Chang $\mathrm{CH}$, Wang KC, Su Cl, Liu HT, Yu CM, et al. Enhancement of rotator cuff tendon-bone healing with injectable periosteum progenitor cells-BMP-2 hydrogel in vivo. Knee Surg Sports Traumatol Arthrosc. 2011;19: 1597-607. https://doi.org/10.1007/s00167-010-1373-0.

7. Chen L, Dong SW, Liu JP, Tao X, Tang KL, Xu JZ. Synergy of tendon stem cells and platelet-rich plasma in tendon healing. J Orthop Res. 2012;30:9917. https://doi.org/10.1002/jor.22033.

8. Cheng B, Ge H, Zhou J, Zhang Q. TSG-6 mediates the effect of tendon derived stem cells for rotator cuff healing. Eur Rev Med Pharmacol Sci. 2014; 18:247-51.

9. Choo A, McCarthy M, Pichika R, Sato EJ, Lieber RL, Schenk S, et al. Muscle gene expression patterns in human rotator cuff pathology. J Bone Joint Surg Am. 2014;96:1558-65. https://doi.org/10.2106/JBJS.M.01585.

10. Gross G, Hoffmann A. Therapeutic strategies for tendon healing based on novel biomaterials, factors and cells. Pathobiology. 2013;80:203-10. https://doi.org/10.1159/000347059.

11. Hernigou P, Flouzat Lachaniette $C H$, Delambre J, Zilber S, Duffiet $P$, Chevallier $\mathrm{N}$, et al. Biologic augmentation of rotator cuff repair with mesenchymal stem cells during arthroscopy improves healing and prevents further tears: a case-controlled study. Int Orthop. 2014;38:1811-8. https://doi. org/10.1007/s00264-014-2391-1.

12. Hogan MV, Bagayoko N, James R, Starnes T, Katz A, Chhabra AB. Tissue engineering solutions for tendon repair. J Am Acad Orthop Surg. 2011;19: 134-42.

13. Karthikeyan S, Griffin DR, Parsons N, Lawrence TM, Modi CS, Drew SJ, et al. Microvascular blood flow in normal and pathologic rotator cuffs. J Shoulder Elb Surg. 2015;24:1954-60. https://doi.org/10.1016/j.jse.2015.07.014.

14. Kisiday JD, Schwartz JA, Tangtrongsup S, Goodrich LR, Grande DA. Culture conditions that support expansion and Chondrogenesis of middle-aged rat Mesenchymal stem cells. Cartilage. 2018. https://doi.org/10.1177/ 1947603518790047.

15. Kopesky PW, Lee HY, Vanderploeg EJ, Kisiday JD, Frisbie DD, Plaas AH, et al. Adult equine bone marrow stromal cells produce a cartilage-like ECM mechanically superior to animal-matched adult chondrocytes. Matrix Biol. 2010;29:427-38. https://doi.org/10.1016/j.matbio.2010.02.003.

16. Lapner PL, Sabri E, Rakhra K, McRae S, Leiter J, Bell K, et al. A multicenter randomized controlled trial comparing single-row with double-row fixation in arthroscopic rotator cuff repair. J Bone Joint Surg Am. 2012;94:1249-57. https://doi.org/10.2106/JBJS.K.00999.

17. Leal MF, Belangero PS, Figueiredo EA, Cohen C, Loyola LC, Andreoli CV, et al. Identification of suitable reference genes for gene expression studies in tendons from patients with rotator cuff tear. PLOS One. 2015;10:e0118821. https://doi.org/10.1371/journal.pone.0118821.

18. Lombana KG, Goodrich LR, Phillips JN, Kisiday JD, Ruple-Czerniak A, Mcllwraith CW. An investigation of equine Mesenchymal stem cell characteristics from different harvest sites: more similar than not. Front Vet Sci. 2015;2:67. https://doi.org/10.3389/fvets.2015.00067.

19. Lui PP, Wong OT, Lee YW. Application of tendon-derived stem cell sheet for the promotion of graft healing in anterior cruciate ligament reconstruction. Am J Sports Med. 2014;42:681-9. https://doi.org/10.1177/ 0363546513517539.

20. Luo W, Sandy J, Trella K, Gorski D, Gao S, Li J, et al. Degenerative suspensory ligament Desmitis (DSLD) in Peruvian Paso horses is characterized by altered expression of TGFbeta signaling components in adipose-derived stromal fibroblasts. PLoS One. 2016;11:e0167069. https://doi.org/10.1371/ journal.pone.0167069.

21. Mather RC 3rd, Koenig L, Acevedo D, Dall TM, Gallo P, Romeo A, et al. The societal and economic value of rotator cuff repair. J Bone Joint Surg Am. 2013:95:1993-2000. https://doi.org/10.2106/JBJS.L.01495.

22. Nagura I, Kokubu T, Mifune Y, Inui A, Takase F, Ueda Y, et al. Characterization of progenitor cells derived from torn human rotator cuff tendons by gene expression patterns of chondrogenesis, osteogenesis, and adipogenesis. J Orthop Surg Res. 2016;11:40. https://doi.org/10.1186/s13018-016-0373-2.

23. Nixon AJ, Watts AE, Schnabel LV. Cell- and gene-based approaches to tendon regeneration. J Shoulder Elb Surg. 2012;21:278-94. https://doi.org/ 10.1016/j.jse.2011.11.015

24. Obaid H, Connell D. Cell therapy in tendon disorders: what is the current evidence? Am J Sports Med. 2010;38:2123-32. https://doi.org/10.1177/ 0363546510373574.

25. Ogawa R, Mizuno H, Watanabe A, Migita M, Shimada T, Hyakusoku H. Osteogenic and chondrogenic differentiation by adipose-derived stem cells harvested from GFP transgenic mice. Biochem Biophys Res Commun. 2004;313:871-7.

26. Oh JH, Chung SW, Kim SH, Chung JY, Kim JY. 2013 Neer award: effect of the adipose-derived stem cell for the improvement of fatty degeneration and rotator cuff healing in rabbit model. J Shoulder Elb Surg. 2014;23:445-55. https://doi.org/10.1016/j.jse.2013.07.054.

27. Petrou IG, Grognuz A, Hirt-Burri N, Raffoul W, Applegate LA. Cell therapies for tendons: old cell choice for modern innovation. Swiss Med Wkly. 2014 144:w13989. https://doi.org/10.4414/smw.2014.13989.

28. Randelli P, Conforti E, Piccoli M, Ragone V, Creo P, Cirillo F, et al. Isolation and characterization of 2 new human rotator cuff and long head of biceps tendon cells possessing stem cell-like self-renewal and multipotential differentiation capacity. Am J Sports Med. 2013;41:1653-64. https:/doi.org/ 10.1177/0363546512473572.

29. Rodeo SA. Biologic augmentation of rotator cuff tendon repair. J Shoulder Elb Surg. 2007;16:S191-7. https://doi.org/10.1016/j.jse.2007.03.012.

30. Rothrauff BB, Tuan RS. Cellular therapy in bone-tendon interface regeneration. Organogenesis. 2014;10:13-28. https://doi.org/10.4161/org.27404.

31. Schar MO, Rodeo SA, Zumstein MA. Biologics in rotator cuff surgery. Shoulder Elbow. 2014;6:239-44. https://doi.org/10.1177/1758573214536536. 
32. Schmutz S, Fuchs T, Regenfelder F, Steinmann P, Zumstein M, Fuchs B. Expression of atrophy mRNA relates to tendon tear size in supraspinatus muscle. Clin Orthop Relat Res. 2009;467:457-64. https://doi.org/10.1007/ s11999-008-0565-0.

33. Sikes KJ, Li J, Gao SG, Shen Q, Sandy JD, Plaas A, et al. TGF-b1 or hypoxia enhance glucose metabolism and lactate production via HIF1A signaling in tendon cells. Connect Tissue Res. 2018;59:458-71. https://doi.org/10.1080/ 03008207.2018.1439483.

34. Sugaya H, Maeda K, Matsuki K, Moriishi J. Repair integrity and functional outcome after arthroscopic double-row rotator cuff repair. A prospective outcome study. J Bone Joint Surg Am. 2007;89:953-60. https://doi.org/10. 2106/JBJS.F.00512.

35. Thomopoulos S, Genin GM, Galatz LM. The development and morphogenesis of the tendon-to-bone insertion - what development can teach us about healing. J Musculoskelet Neuronal Interact. 2010;10:35-45.

36. Tsai CC, Huang TF, Ma HL, Chiang ER, Hung SC. Isolation of mesenchymal stem cells from shoulder rotator cuff: a potential source for muscle and tendon repair. Cell Transplant. 2013;22:413-22. https://doi.org/10.3727/ $096368912 \times 656090$.

37. Utsunomiya H, Uchida S, Sekiya I, Sakai A, Moridera K, Nakamura T. Isolation and characterization of human mesenchymal stem cells derived from shoulder tissues involved in rotator cuff tears. Am J Sports Med. 2013;41 657-68. https://doi.org/10.1177/0363546512473269.

38. Virk MS, Sugiyama O, Park SH, Gambhir SS, Adams DJ, Drissi H, et al. "Same day" ex-vivo regional gene therapy: a novel strategy to enhance bone repair. Mol Ther. 2011;19:960-8. https://doi.org/10.1038/mt.2011.2

39. Visotsky JL, Basamania C, Seebauer L, Rockwood CA, Jensen KL. Cuff tear arthropathy: pathogenesis, classification, and algorithm for treatment. J Bone Joint Surg Am. 2004;86-A(Suppl 2):35-40.

40. Yang G, Rothrauff BB, Tuan RS. Tendon and ligament regeneration and repair: clinical relevance and developmental paradigm. Birth Defects Res $C$ Embryo Today. 2013;99:203-22. https://doi.org/10.1002/bdrc.21041.

41. Zhang J, Wang JH. Characterization of differential properties of rabbit tendon stem cells and tenocytes. BMC Musculoskelet Disord. 2010;11:10. https://doi.org/10.1186/1471-2474-11-10

\section{Publisher's Note}

Springer Nature remains neutral with regard to jurisdictional claims in published maps and institutional affiliations.

Ready to submit your research? Choose BMC and benefit from:

- fast, convenient online submission

- thorough peer review by experienced researchers in your field

- rapid publication on acceptance

- support for research data, including large and complex data types

- gold Open Access which fosters wider collaboration and increased citations

- maximum visibility for your research: over $100 \mathrm{M}$ website views per year

At $\mathrm{BMC}$, research is always in progress.

Learn more biomedcentral.com/submissions 